\title{
Prevention and control of iodine deficiency in pregnant and lactating women and in children less than 2-years-old: conclusions and recommendations of the Technical Consultation
}

\author{
WHO Secretariat on behalf of the participants to the Consultation ${ }^{\dagger}$ \\ $M$ Andersson $^{1}$, B de Benoist ${ }^{2 *}$, F Delange $^{3}$ and J Zupan ${ }^{4}$ \\ 'Department of Nutrition for Health and Development, World Health Organization, Present address: Laboratory for \\ Human Nutrition, Swiss Federal Institute of Technology, Seestrasse 72, Postfach 474, 8803 Rüschlikon, ZH, \\ Switzerland: ${ }^{2}$ Department of Nutrition for Health and Development, World Health Organization, 20 Avenue Appia, \\ Geneva, Switzerland: ${ }^{3}$ ICCIDD, Avenue de la Fauconnerie 153, Boisfort, B 1170 Brussels, Belgium: ${ }^{4}$ Department of \\ Reproductive Health and Research, World Health Organization, 20 Avenue Appia, Geneva, Switzerland
}

The Consultation reached a general consensus on several important issues. First, that universal salt iodisation $\neq$ (USI) remains the key strategy to eliminate iodine deficiency disorders. Second, that where USI has been effective for at least 2 years, with salt adequately iodised and consumed by more than $90 \%$ of the population ${ }^{1}$, it can be reasonably expected that the iodine needs of women of child-bearing age and pregnant and lactating women are covered by their diet, and that the iodine stored in the thyroid gland is sufficient to ensure adequate hormone synthesis and secretion. Third, that iodised salt may not provide enough iodine to meet a child's needs during complementary feeding, especially if the mother is only marginally iodine sufficient, unless complementary foods are fortified with iodine. It may be necessary therefore to give additional iodine to make sure that requirements are met until such time as the child starts to eat the normal family food. Finally, there was consensus that monitoring of both iodised salt quality and iodine nutrition are important to ensure that an optimal state of iodine nutrition is reached and then sustained.

The Consultation made several specific recommendations concerning requirements, indicators and strategies to control iodine deficiency disorders in pregnant and lactating women, and in children less than 2-years-old.

\section{Iodine requirements}

The starting point for the Technical Consultation was the current $\mathrm{FAO} / \mathrm{WHO}$ recommended iodine intakes ${ }^{2}$ and

\footnotetext{
${ }^{\dagger}$ The members of the WHO Secretariat included M Andersson, B de Benoist, F Delange and J Zupan.

${ }^{*}$ Universal Salt Iodisation USI means the iodisation of salt for consumption by both humans and animals.

${ }^{s}$ The recommended nutrient intake (RNI) is the daily intake, set at the estimated average requirement (EAR) plus 2 standard deviations, in order to meet the nutrient requirements of $98 \%$ of individuals in an age- and sex-specific population group. The definition of RNI is equivalent to that of the recommended dietary allowance (RDA) used by the Food and Nutrition Board of the United States Institute of Medicine (reference 3).
}

whether the amounts were sufficient to prevent brain damage or thyroid function disorders due to an iodine deficiency during pregnancy, lactation and the first 2 years of life. A recommended nutrient intake ${ }^{\S}$ (RNI) is typically set at an amount that meets the needs of almost all apparently healthy individuals in a specified sex and age group. Because of the lack of data on what comprised a sufficient intake, the Consultation estimated the needs of each group by applying what is known about the efficiency with which iodine is absorbed from the gut, the estimated metabolic needs, and the typical daily losses in the faeces and urine, taking into account increased glomerular filtration in pregnant women. Based on these assumptions, the proposed intakes are shown in Table 1.

\section{Pregnancy}

The Technical Consultation proposed to increase the current FAO/WHO RNI for iodine during pregnancy ${ }^{2}$ from 200 to $250 \mu \mathrm{g} \mathrm{day}^{-1}$ (Table 1 ). A daily intake greater than $500 \mu \mathrm{g} \mathrm{day}^{-1}$ is not necessary as it would not provide any additional benefit for health and theoretically may be associated with impaired thyroid function ${ }^{2,3}$. However, the scientific evidence for this is weak because the risk is related to the history of iodine nutrition in the specific population before the correction of an iodine deficiency, and the risk is greater in formerly iodine deficient populations. Nevertheless, it was considered important to monitor the risk of thyroid disease due to an excessive consumption of iodine, as well as due to deficiency.

\section{Lactation}

During lactation, the physiology of thyroid hormone production and urinary iodine (UI) excretion returns to normal, but iodine is concentrated in the mammary gland for excretion in breast milk. Thus, using the UI concentration to estimate intake may lead to an underestimate of requirements. But because of the need to ensure that the infant gets enough iodine from breast milk to build reserves in the thyroid gland, it was recommended 
Table 1 The daily recommended nutrient intake (RNI) for iodine proposed for pregnant and lactating women, and children less than 2-years-old, and the daily intake that is considered should not to be exceeded.

\begin{tabular}{lcc}
\hline & $\begin{array}{c}\text { Recommended } \\
\text { iodine intake } \\
\left(\mu \text { day }^{-1}\right)\end{array}$ & $\begin{array}{c}\text { Level of iodine intake beyond } \\
\text { which no added health benefit } \\
\text { can be expected }\left(\mu \mathrm{g} \mathrm{day}^{-1}\right)\end{array}$ \\
\hline Population group & 250 & $>500$ \\
Pregnant women & 250 & $>500$ \\
Lactating women & 90 & $>180$ \\
Children less than & & \\
2-years-old & & \\
\hline
\end{tabular}

that lactating women should continue to consume $250 \mu \mathrm{g}$ of iodine per day This also represents an increase in the recommended intake of iodine by $50 \mu \mathrm{g} \mathrm{day}^{-1}$ compared with the previous $\mathrm{RNI}^{2}$. A daily intake greater than $500 \mu \mathrm{g} \mathrm{day}^{-1}$ is not necessary as it would not provide any additional benefit for health and theoretically may be associated with impaired thyroid function ${ }^{2,4}$

\section{Children less than 2-years-old}

For children less than 2-years-old, the previously recommended iodine intake of $90 \mu \mathrm{g} \mathrm{day}^{-1}$ remains the same ${ }^{2}$. There was no attempt to propose a recommended iodine intake for preterm infants because of the lack of data.

\section{Indicators to assess iodine status and monitor impact}

Most of the iodine absorbed by the body is eventually excreted in the urine, although there may be small losses in faeces. Although the concentration of iodine in the urine of an individual can vary diurnally and from day-today, the concentration of iodine in spot or casual samples of urine taken from an adequate sample of schoolchildren has been shown to be a reliable biochemical marker of recent dietary intake by the general population of the same area when measured using recommended methods ${ }^{1}$. For this reason, the Consultation proposed that the median UI concentration was the best indicator to use in population surveys to assess the iodine nutrition of pregnant and lactating women, and of young children less than 2-years-old. However, further studies are required to provide better support for this statement (see below). Moreover, this indicator should not be used for the purposes of individual diagnosis and treatment. As an indicator of iodine intake, median UI concentration does not provide direct information about thyroid function. However, a low median UI concentration indicates that a population is at risk of developing thyroid disorders.

If it is assumed that $90 \%$ of iodine intake is excreted in the urine during pregnancy and that the average volume of urine is $1.51 \mathrm{day}^{-1}$, then of every $100 \mu \mathrm{g}$ of iodine ingested, $90 \mu \mathrm{g}$ is excreted in urine at a concentration of $60 \mu \mathrm{gl}^{-1}$. This can be used as the basis to estimate iodine intake from the median iodine concentration in the urine of pregnant women. The median concentration of iodine in the urine of samples of children less than 2-years-old could also be used to assess their iodine intake, and thus their iodine status, using the same calculation as for pregnant women, but assuming an average volume of urine of $300-500 \mathrm{mlday}^{-1}$. The main problem lies in collecting urine samples from this age group.

The Technical Consultation recommended that iodine status should be assessed in surveys conducted every 3-5 years using methods that have been well described ${ }^{1}$.

Table 2 shows the median UI concentrations proposed to classify pregnant women, lactating women and children aged 0-2-years-old into categories of iodine intake.

In countries or regions in which systematic neonatal screening for congenital hypothyroidism is done using the concentration in blood of thyroid-stimulating hormone (TSH), an elevated concentration of TSH reflects an insufficient supply of maternal and/or foetal thyroid hormone to the developing brain and indicates a risk of irreversible brain damage ${ }^{5}$. However, the Consultation recognised that the use of serum TSH concentration as an indicator needs further validation to establish and then standardise when and how to collect blood samples after birth, and more data are required to establish a threshold to interpret the results.

\section{Strategies to control iodine deficiency in pregnant and lactating women, and in children between birth and 24 months of age Country by category}

Where iodine deficiency is a public health problem, countries can be divided broadly into three categories based on national salt iodisation coverage.

- Category 1. Countries or regions within countries in which iodine deficiency is under control in a sustained way because salt iodisation has been effective for more than 2 years. This is indicated by the fact that iodised salt is consumed by more than $90 \%$ of households and that

Table 2 The median or range in urinary iodine (UI) concentrations used to categorise the iodine intake of pregnant women, lactating women and children less than 2-years-old.

\begin{tabular}{|c|c|c|}
\hline Population group & $\begin{array}{c}\text { Median UI } \\
\text { concentration } \\
\left(\mu \mathrm{gl}^{-1}\right)\end{array}$ & $\begin{array}{l}\text { Category of } \\
\text { iodine intake }\end{array}$ \\
\hline Pregnant women & $\begin{array}{l}<150 \\
150-249 \\
250-499 \\
\geq 500\end{array}$ & $\begin{array}{l}\text { Insufficient } \\
\text { Adequate } \\
\text { More than adequate } \\
\text { No added health } \\
\text { benefit expected }\end{array}$ \\
\hline Lactating women $^{\mathrm{a}}$ & $\begin{array}{l}<100 \\
\geq 100\end{array}$ & $\begin{array}{l}\text { Insufficient } \\
\text { Adequate }\end{array}$ \\
\hline $\begin{array}{l}\text { Children less than } \\
2 \text {-years-old }\end{array}$ & $\begin{array}{l}<100 \\
\geq 100\end{array}$ & $\begin{array}{l}\text { Insufficient } \\
\text { Adequate }\end{array}$ \\
\hline
\end{tabular}

${ }^{\mathrm{a}}$ In lactating women, the figures for median UI are lower than the iodine requirements because of the iodine excreted in breast milk. 
iodine nutrition is optimal according to WHO criteria, including in pregnant women and children less than 2-years-old ${ }^{1}$.

- Category 2. Countries or regions within countries in which not all salt is iodised, salt iodisation is not regulated, or the distribution of iodised salt is uneven or has lapsed so that less than 90\% of the households consume iodised salt and iodine nutrition is inadequate.

- Category 3. Countries or regions within countries in which iodised salt is either not available or available only to a negligible extent, either because the distribution system is weak or because an emergency has severely disrupted iodised salt supplies. In this category, it is assumed that less than $20 \%$ of the households consume iodised oil and iodine nutrition is inadequate.

Table 3 shows thresholds of median UI concentration that could be used to help decide into which category a country-or a geographical or administrative region within a country-falls.

This categorisation is proposed because it is the easiest one to apply, given the data currently available in most countries. However, the Consultation recognised that it has limitations as the prevalence of households reached by iodised salt at a national level may mask variations within the countries among regions or districts: some may have achieved USI, but this may not be the case at national level while some regions or districts may not have reached USI although the country has. In other words, the policy on iodine supplementation for pregnant women and young children should, as much as possible, be adjusted to take into account such variations within the country. This may require an assessment of iodised salt coverage prior to designing a programme of supplementation.

\section{Recommended approaches to give additional iodine to pregnant and lactating women, and to children less than 2-years-old}

There are two main approaches to giving supplementary iodine: either on a daily basis, typically using potassium iodide, or on an annual basis, using a slowly released iodine preparation such as iodised oil. The approach used depends on the accessibility of the populations to be reached. Moreover, given the fact that the dietary iodine content may vary in different populations, the amount of iodine given as a supplement should be based on a prior assessment of the current iodine intake by the population so that the total amount of daily iodine consumed, including the iodine supplement, does not exceed the RNI (see Table 1).

Category 1. Countries or regions within countries with effective and sustained salt iodisation (more than 90\% of the bousebolds consumed iodised salt)

In the first group of countries or regions within countries, the population is considered to be iodine sufficient; so pregnant and lactating women have no need for iodine supplements, nor do children aged 0-24-months-old require them. Indeed, the amount of iodine stored in the thyroid of a child at birth, when added to the iodine intake from the mother's breast milk, is likely to be sufficient to meet a child's need for iodine for the first 6 months of life and even up to 24 months of age.

Category 2. Countries or regions within the countries with uneven or lapsed iodised salt distribution (the proportion of the bousebolds consuming iodised salt is between 20 and 90\%)

In the second group of countries or regions within countries, iodine intakes are generally insufficient to meet iodine requirements and do not protect the foetus and young child against the adverse effects of iodine deficiency, especially on brain development. Therefore, while measures should be taken to ensure that effective USI is implemented in conjunction with a programme of public education, iodine supplements are needed by pregnant and lactating women. They are also needed by women of child-bearing age to allow them to start pregnancy with enough stored iodine to meet both their own needs and the needs of their foetus. On the other hand, in children from birth to 24 months of age, although iodised oil can be considered as safe to give, there are few data on its efficacy in this age group; so additional iodine intake should be given through breast milk from a mother supplemented with iodine and, in elder children, through complementary foods fortified with iodine. The following is recommended:

- Women of child-bearing age should be given a daily oral dose of iodine as potassium iodide, so that the total iodine intake meets the RNI of $150 \mu \mathrm{g}$ of iodine per $\mathrm{day}^{2}$; or a single annual oral dose of $400 \mathrm{mg}$ of iodine as iodised oil should be given. At the same time, measures should be taken to educate this group about why and how to prevent iodine deficiency.

- Pregnant and lactating women should be given a daily oral dose of iodine as potassium iodide so that the total iodine intake meets the RNI of $250 \mu \mathrm{g}$ of iodine per day (Table 1), either alone or in combination with other mineral and vitamin supplements; or a single annual oral dose of $400 \mathrm{mg}$ of iodine as oral iodised oil should be given. Iodine supplements should not be given if the mother has already received iodised oil either during her current pregnancy or up to 3 months before her current pregnancy started.

- Children 0-6 months of age should be given additional iodine to meet their daily requirements through breast milk. This implies that the child is exclusively breast-fed and the mother received iodine supplements during pregnancy or lactation as indicated in the above paragraphs.

- Children 7-24 months of age should be given additional iodine through complementary foods 
Table 3 Strategies to control iodine deficiency in pregnant and lactating women, and in children between birth and 24 months of age ${ }^{\text {a }}$.

Category 3 (less than $20 \%$ of median $\mathrm{UI}^{\mathrm{b}}<20 \mu \mathrm{gl}^{-1}$ households using iodised salt)

Approaches to give additional iodine to each population group
Women of reproductive age

a) USI

a) Give iodine supplement:

As a daily oral dose of iodin

as potassium iodide so that

the total iodine intake is

$1 \mathrm{RNI}$ or $150 \mu \mathrm{g}$ of iodine

per day or as a single annual

as iodised oil

a) Give iodine supplement: As a single annual oral dose of $400 \mathrm{mg}$ of lodine as a daily oral dose of iodine as potassium iodide so that the total iodine intake is $1 \mathrm{RNI}$ or $150 \mu \mathrm{g}$ of iodine per day lodised oil or if feasible, as

Pregnant and lactating women

a) USI

a) Give iodine supplement: As a daily oral dose a) Exclusive breast-feeding. of iodine as potassium iodide so that the total b) Measure should be taken so iodine intake is $1 \mathrm{RNI}$ or $250 \mu \mathrm{g}$ of iodine per day, either alone or combined with other minerals and vitamins or as a single annua that the mother received iodine supplements durin pregnancy and lactation b) lodine supplements should not be given if the mother has received iodised oil during her current pregnancy or up to 3 months before her pregnancy started

a) Give iodine supplement: As a single annual oral dose of $400 \mathrm{mg}$ of iodine as iodised oil or if feasible, as a daily oral dose of iodine as potassium iodide so that the total iodine intake is $1 \mathrm{RNI}$ or $250 \mu \mathrm{g}$ of iodine per day, either alone or combined with other minerals and vitamins. b) lodine supplements should not be given if the mother has already received

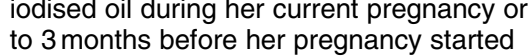

a) Exclusive breast-feeding.

Thas the should be taken so that the mother received iodine supplements during pregnancy and lactation a) Give additional iodine as soon as possible after 6 months throug complementary foods fortified should be sustained with iodine. b) Breast-feeding

a) Give additional iodine as soon as possible after 6 months throug complementary foods fortified with iodine. b) Breast-feeding should be sustained

${ }^{a}$ The strategies should be adapted according to local conditions.

${ }^{\mathrm{b}} \mathrm{Ul}$ stands for urinary iodine. 
fortified with iodine. Breast-feeding should be sustained.

Category 3. Countries or regions within the countries with weak or negligible iodised salt distribution (less than 90\% of the bousebolds consumed iodised salt)

In the third group of countries or regions within countries, despite their poor iodine nutrition, populations do not receive any additional iodine in the form of supplements or iodised salt. Such populations should be given supplements focussing on pregnant women, lactating women and women of child-bearing age. Since such people may live in remote areas or may experience an emergency, it may not be possible to deliver a daily iodine supplement, so giving iodised oil may be a better option. In children from birth to 24 months of age, for the reasons given in the previous paragraph, additional iodine intake should be given through breast milk from a mother supplemented with iodine and, in elder children, through complementary foods fortified with iodine. However, there may be some situations where the child is not breastfed; given the heath consequences of iodine deficiency, iodine supplementation should be considered for such children. Moreover, strong efforts should be made to establish or reinstitute USI and to ensure that iodised salt is distributed widely. The following is recommended:

- Women of child-bearing age should be given a single annual oral dose of $400 \mathrm{mg}$ of iodine as iodised oil; or, if feasible, a daily oral dose of iodine as potassium iodide should be given so that the total iodine intake meets the RNI of $150 \mu \mathrm{g}$ of iodine per day. At the same time, measures should be taken to educate this group about why and how to prevent an iodine deficiency.

- Women who are currently pregnant or lactating should be given a single annual oral dose of $400 \mathrm{mg}$ of iodine as iodised oil; or, if feasible, a daily oral dose of iodine as potassium iodide should be given so that the total iodine intake meets the RNI of $250 \mu \mathrm{g}$ of iodine per day. Iodine supplements should not be given to women who have already been given iodised oil during her current pregnancy or up to 3 months before her current pregnancy started.

- Children 0-6 months of age should be given additional iodine to meet their daily requirements through breast milk. This implies that the child is exclusively breast-fed and the mother received iodine supplements during pregnancy or lactation as indicated in the above paragraphs. Iodine supplementation should be considered where the child is not breast-fed.

- Children 7-24 months of age should be given additional iodine through complementary foods fortified with iodine. Breast-feeding should be sustained.

These recommendations are summarised in Table 3. These dosages are considered to be safe to administer ${ }^{6}$.

\section{Priorities for research}

Several priorities for research were identified concerning the physiology and metabolism of iodine during pregnancy and early infancy. A particular emphasis was placed on the importance of a multidisciplinary approach involving nutritionists, endocrinologists, obstetricians and paediatricians. Specific studies were proposed on:

- Risk factors for iodine deficiency and its functional consequences including:

$\checkmark$ the relationships between a high intake of iodine and thyroid disease and function, especially in neonates and infants;

- breast milk iodine concentration;

o the influence of smoking on iodine status and breast milk iodine concentration;

o the impact of iodine supplements on cognitive development and intellectual outcomes through randomised, controlled trials; and

$\circ$ the metabolic interactions between iodine and other micronutrients in the situation of iodine deficiency.

- Indicators and assessment of iodine status including:

0 the identification of the best indicators to assess iodine nutrition and monitor the impact of interventions to control iodine deficiency during pregnancy, lactation and the first 2 years of infancy;

$\checkmark$ the relationship between the iodine status of schoolchildren and the iodine status of pregnant women in the same location, to see whether school-age children, the usual indicator group, are the most appropriate group to reflect the iodine status of pregnant women and young children less than 2 years of age;

- the median UI concentration that corresponds to an excessive iodine intake in pregnant and lactating women, and children less than 2 years of age;

- the prevalence of iodine deficiency in pregnant and lactating women, and children less than 2 years of age; and

- standardisation of the measurement and interpretation of serum TSH in neonates.

- Approaches to controlling iodine deficiency including:

- strategies to advocate the iodisation of salt and to market iodised salt;

- factors that hamper the consumption of iodised salt, including the effect of a diminishing salt intake due to the risks of hypertension;

- complementary strategies - in addition to iodised salt - to provide iodine to children $0-24$ months of age, in particular, during the complementary feeding period;

0 the bioavailability of iodine as iodised oils and the optimum dose of iodised oil to give to pregnant women, lactating women and infants; and 
$\circ$ the development of new pharmaceutical preparations of iodine.

\section{References}

1 WHO, UNICEF, ICCIDD. Assessment of Iodine Deficiency Disorders and Monitoring Their Elimination. A Guide for Programme Managers. (WHO/NHD/01.1), 2nd ed. Geneva: World Health Organization, 2001. http://www.who.int/nut/ documents/assessment_idd_monitoring_eliminination.pdf

2 FAO, WHO. Vitamin and Mineral Requirements in Human Nutrition, 2nd ed. Geneva: World Health Organization, 2005. http://whqlibdoc.who.int/publications/2004/9241546123.pdf

3 Food and Nutrition Board, Institute of Medicine. Dietary Reference Intakes for Vitamin A, Vitamin K, Arsenic, Boron, Chromium, Copper, Iodine, Iron, Manganese, Molybdenum, Nickel, Silicon, Vanadium and Zinc. A Report of the Subcommittee on Interpretation and Uses of Dietary Reference
Intakes and the Standing Committee on the Scientific Evaluation of Dietary Reference Intakes. Washington, DC: National Academy Press, 2000 http://www.nap.edu/books/ 0309072794/html/

4 Food and Nutrition Board, Institute of Medicine. Dietary Reference Intakes for Vitamin A, Vitamin K, Arsenic, Boron, Chromium, Copper, Iodine, Iron, Manganese, Molybdenum, Nickel, Silicon, Vanadium and Zinc. A Report of the Subcommittee on Interpretation and Uses of Dietary Reference Intakes and the Standing Committee on the Scientific Evaluation of Dietary Reference Intakes. Washington, DC: National Academy Press, 2000 http://www.nap.edu/books/ 0309072794/html/

5 Delange F. Screening for congenital hypothyroidism used as an indicator of the degree of iodine deficiency and of its control. Thyroid 1998; 8: 1185-92.

6 WHO. The safe use of iodized oil during pregnancy. Bulletin of the World Health Organization 1996; 74: 1-3. (http:// whqlibdoc.who.int/hq/1996/WHO_NUT_96.5.pdf) 